\title{
ALK NP_004295.2:p.F1174V
}

National Cancer Institute

\section{Source}

National Cancer Institute. ALK NP 004295.2:p.F1174V. NCI Thesaurus. Code C146869.

A change in the amino acid residue at position 1174 in the ALK tyrosine kinase receptor protein where phenylalanine has been replaced by valine. 